sorting books and identifying problems; and treatment. Nothing is left to the imagination of the novice (as indeed it shouldn't be), and the first section describes such basic steps as how to improvise work areas, how to move books, how to keep track of them as they are sorted and treated.

The section on sorting explains, among many other things, how to recognize acid migration, how case bindings are made and thus what to do with books that are loose in their cases, how to distinguish between real and artificial leather in sorting books for oiling. The suggestion I'm grateful for is how to deal with the untitled slip case that has to be separated from its book: write author, title, and call number on a large sheet of paper and then crumple it up inside the case. No more the empty case that has to be discarded because it won't fit any book except the one that returned to the shelf without it.

The section on treatment is concise, explicit, and fascinating. It presents the essential facts about preserving leather bindings, explains the need for treating leather with potassium lactate, tells exactly which leather dressing to use and how to apply it. It tells-and of course shows-how to make simple repairs on torn leaves, how to rebuild corners, how and where to paste bookplates.

It also describes how to hinge letters in books, on the assumption that "in a private collection or rare-book room, letters from the author, unless very bulky, are usually kept with the book" (p. 23). Mrs. Horton is justified in describing the proper way to hinge letters in books but I doubt that most experienced rare book librarians would recommend it. Perhaps in the second edition (which is certain to be called for) she would describe the technique but accentuate her alternative suggestion of filing the letter in a separate folder "where it cannot damage the book in any way" (p. 25).

A detailed table of contents substitutes for an index, while the back matter consists of a glossary, a list of supplies and equipment mentioned in the text (all used by Mrs. Horton or known by her to be in general use and to perform in an acceptable manner), a list of stores where the supplies can be bought, and a selected bibliography.
The pamphlet is printed on 8\% $\mathrm{x}$ 11-inch 'Permalife' paper, has wide margins, large type, and a stylish blending of text and illustration. Its permanance, its pleasing appearance are singularly appropriate for a manual that will be in constant use by everybody concerned with preserving books. -Marjorie G. Wynne, The Beinecke Rare Book and Manuscript Library, Yale University.

\section{EDUNET: A Report of the Summer Study on Information Networks Conducted by the Interuniversity Communications} Council (EDUCOM). By George W. Brown, James G. Miller, Thomas A. Keenan. New York: Wiley, 1967. xix, 440p. \$3.95. (67-21328).

With a $\$ 750,000$ grant from the Kellogg Foundation the Interuniversity Communications Council came into existence and joined the ranks of organizations that are concerned with developing cooperative programs among colleges and universities. The Council was the brainchild of James A. Miller of the University of Michigan, who was responsible for obtaining the five-year grant, organizing the initial programs, and steering the new activity on a course that has been grandiose and ambitious and holds the promise of great potential for the educational community. Dr. Miller, a physician by training, while stressing the importance of cooperative efforts in all fields, was particularly interested in having the new organization act as a unified voice for the educational world in matters of educational and communications technology. Such an organization could work with government and industry as an equal partner to insure that its point of view was always represented.

The initial efforts of the Council were of an organizational nature, and time was spent identifying means by which it could carry out its mission and develop action programs. As the number of member universities and colleges grew, the Council focused its attention on specific programs for exchanging and sharing intellectual and human, library and computer resources. Great attention was also given to the need for utilizing all available technology, such 
as educational TV, computer-assisted instruction, and continuing education, to improve the educational process. The Council, which soon became known by the acronym EDUCOM, did not restrict its mission to any field.

The first tangible effort to develop an action program was begun by the Task Force on Information Networks, under the chairmanship of George W. Brown of UCLA. The Task Force was charged with investigating a way by which a network could be established and was asked to prepare a proposal to seek the necessary funding for establishment of a pilot operation. With the state of the art of network technology still unclear, there was need to obtain technical advice and also to explore numerous other considerations. In July 1966 the Task Force, with small grants from several federal agencies, assembled at the University of Colorado 181 persons from education, government, and industry, to assist in the preparation of the proposal. The EDUNET Conference, as it came to be known, delved into all possible ramifications of a network system for the educational community, the definition of needs, network applications, organizational and institutional context, and finally the preparation of a specific network proposal. Those in attendance were asked to prepare working papers on the above-mentioned topics, which in turn served as the basis for extensive discussion. More than one hundred and fifty working papers were written during the study. Plenary sessions were used to pull together much of the work. The conference proceedings first appeared as a preliminary draft dated September 1966 and had a very limited circulation. This draft was used as the basis for the publication now under review. Although some editorial work appears evident in the final version, the material is presented here in the same form, and there are very few changes. The working papers do not appear in full, but extracts are taken from each, with the author and area of application cited. The extracts have been arranged in a reasonably logical sequence and are held together by comments and brief narratives. What emerges is essentially a series of short statements by many people rather than an edited and polished presentation. For this reason there is much unavoidable redundancy, and one finds many recurring topics. Although the book is an important summary of the views of many knowledgeable people from a variety of backgrounds and training, it is probably not a volume that will be read from cover to cover. As to the material that appears in the volume, there is no doubt that a very substantial case is set forth for the need of a network and that sufficient evidence is presented to demonstrate that there are shareable machine-readable resources that could be used to establish a pilot network. It would have been interesting if some of those in attendance at the conference had presented a case for not establishing a network.

It is impossible to comment on the many extracts cited, but the views of J. C. Licklider of IBM and John Carr of the University of Pennsylvania are especially worth noting. Mr. Licklider feels that the system should consist essentially of a network of networks and that one of the valuable things that EDUCOM can do is to maintain a central registry or directory of networks and related resources. Prof. Carr stresses the need for standardization and system compatibility feeling that EDUCOM should be responsible for standardizing "on-line communications up to the interface with the members, and the members should have the responsibility of meeting these standards. . . " Throughout the volume, many diverse views are presented, and it is to the credit of the editors that the main message - the need for improving the educational and research process by the sharing of each others' resources through a network-comes through.-John P. McGowan, Northwestern University.

Library Surveys. Ed. by Maurice F. Tauber and Irene Roemer Stephens. N.Y.: Columbia University Press, 1967. xxii, 286 p. $\$ 13.50$ (67-25304)

The present collection of papers by leading lights in the somewhat esoteric world of library surveys is based upon a Conference on Library Surveys, held at Columbia University in June 1965. The expanding interest in the general theme is shown by the recent publication in England of a work with the same title, Maurice B. 